Saudi Journal of Medicine

Abbreviated Key Title: Saudi J Med ISSN 2518-3389 (Print) |ISSN 2518-3397 (Online)

\title{
Nerve Injury Following Implant Placement or Complications Following Implant Placement: A Review
}

Dr. Nabaprakash Sahu MDS ${ }^{1 *}$, Dr. Rohini Kanitkar; MDS- OMFS, FCCS (Swiss) ${ }^{2}$, Dr. Soumyasnata Maiti ${ }^{3}$, Dr. Rahul Vinay Chandra Tiwari, FOGS, MDS ${ }^{4}$, Dr. Ravleen Khalsa ${ }^{5}$, Dr. Amit Shivakant Vathare, MDS ${ }^{6}$, Dr. Pritee Rajkumar Pandey, PG, OMFS, $\mathrm{DJ}^{7}$

\author{
${ }^{1}$ Prosthodontics, Crown \& Bridges, Reader, Department Of Prosthodontics, Hi-Tech Dental College \& Hospital, Health Park, Pandara, Rasulgarh, \\ Bhubaneswar, Odisha India \\ ${ }^{2}$ Consultant Oral and Maxillofacial Surgeon, Pune, Maharashtra India \\ ${ }^{3} \mathrm{Pg}$ Student, Dept of OMFS, KLE Belgaum, Karnataka India \\ ${ }^{4}$ Consultant Oral \& Maxillofacial Surgeon, CLOVE Dental \& OMNI Hospitals, Visakhapatnam, Andhra Pradesh, India \\ ${ }^{5}$ Consultant Prosthodontist Crown \& Bridge, Rashi Dental Clinic, Above wardhamaan bank, Nagpur, Maharashtra. \\ ${ }^{6}$ Prosthodontist \& Implantologist, Jaysingpur, Shirol, Kolhapur, Maharashtra India \\ ${ }^{7}$ College of Dental Sciences \& Research, Ajit Mahal, Modinagar - Niwari Rd, Modinagar, Uttar Pradesh, India.
}

DOI: $\underline{10.36348 / \mathrm{sjm} .2020 . \mathrm{v} 05 \mathrm{i} 02.011}$

| Received: 06.02.2020 | Accepted: 20.02.2020 | Published: 22.02.2020

*Corresponding author: Dr. Nabaprakash Sahu MDS

\section{Abstract}

Implant treatment is regarded as a safe technique with high rates of success. Nevertheless, it has, as every surgical procedure, several complications that can occur and that must be known in order to prevent or solve them. Implant surgery complications are frequent occurrences in dental practice and knowledge in the management of these cases is essential. While dental implants are increasingly becoming the choice of replacement for missing teeth, the impediments associated with them are progressively emerging too. The aim of this review was to highlight the challenges of treatment plan-related, anatomy related and procedure-related surgical complications as well as to discuss the etiology, management and treatment options to achieve a satisfactory treatment outcome.

Keywords: Implant, Failure, Complications.

Copyright @ 2020: This is an open-access article distributed under the terms of the Creative Commons Attribution license which permits unrestricted use, distribution, and reproduction in any medium for non-commercial use (NonCommercial, or CC-BY-NC) provided the original author and source are credited.

\section{INTRODUCTION}

Dental implant therapy is a well-established dental treatment modality that provides benefits for edentulous and partially edentulous patients. Edentulism is a toothless condition that affects wellbeing and life quality. Although the prevalence of complete tooth loss has declined since 2002, edentulism remains a major disease worldwide, especially among older adults.1 Studies have demonstrated that dental caries and periodontal diseases are frequent reasons for tooth extraction 2-5. Survival rates of dental implants are reported to be very high in the recent literature [69]. These rates seem to indicate minimal complications with dental implants, however, careful consideration should be taken prior to implant placement as periimplantitis and other problems can be encountered
$[10,11]$. It is important to note the difference between implant survivals and implant success. Implant survival describes an implant that an implant that is still in place. It does not consider factors such as mobility, bone loss, peri-implant disease, and so on. Alternatively, implant success defines an implant that is healthy and fully functional within the oral cavity [12]. When other factors such as bone loss are considered, long term follow up of dental implants may reveal success rates lower than the reported survival. Smoking, male gender, edentulism, implant diameter, and bone augmentations are previously identified risk factors for early implant failure [13]. The aim of the current review is to discuss specific complications associated with dental implants. 


\section{Complications Associated With Dental Implants}

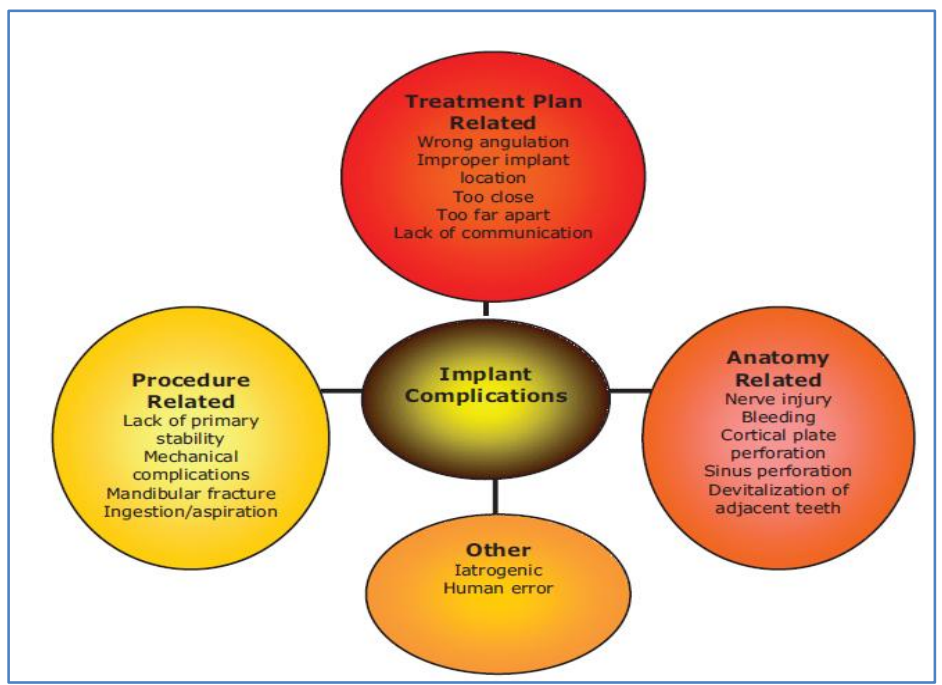

Fig-1: Common complication of implant placement

The majority of problems that can arise in an implantology treatment are accidents, complications or iatrogenic errors, and are a consequence of an inadequate indication, poor quality or quantity of bone, an erroneous surgical technique, infections, lack of oral hygiene, smoking habit, systemic diseases that were poorly controlled. Poor patient selection is one of the important factors that adversely contribute toward failures in implant dentistry [14].

\section{Screw loosening}

Goodacre et al. [15] stated that screw loosening or fracture prevailed more with the prosthetic screws as opposed to the abutment screws. Implants restored with single crowns have shown more screw loosening as compared to multiple implants with multiple restored units, and mandibular molar implant restorations are more affected by screw loosening as compared to the maxillary ones. Over the course of years, many manufacturers have revised the conventional implant components to reduce the incidents of screw loosening [16].

\section{Implant displacement}

The invasion of the maxillary sinus by an implant can occur during or after the surgery as a result of an insufficient primary stability. It has been reported a case of an implant which had been implanted 9 months earlier during a maxillary sinus lift surgery, and which was found inside the sinus only a few days after having placed the fixture.

\section{Mandibular fracture}

Mandibular fracture, during implant placement, is associated with atrophic mandibles. The central area of the mandible has a greater risk for this complication because it has a poor vascular irrigation, which sometimes makes very difficult for the bone and periosteum to provide enough blood for the healing process derived from an implant placement.

\section{Screw/implant fracture}

There are two major causes of implant fracture biomechanical overloading and peri-implant vertical bone loss [17]. The risk of implant fracture increases multifold when the vertical bone loss is severe enough to concur with the apical limit of the screw $[19,20]$.

Implant fractures are also attributable to flaws in the designs and manufacturing of implant itself [21]. Unnoticed and recurrent screw loosening is a risk factor for dental implant fracture, which indicates change in the prosthesis design [22].

\section{Cement failure}

Cement failure is another consequence of biomechanical overload, typically affects the prosthesis attachment and may be treated by recementation procedure [21].

\section{Nerve Injury}

When placing implants in the mandible, proper radiographs and pretreatment planning must be done to ensure complete aversion of the inferior alveolar, mental, incisive or lingual nerves. If the mandibular canal cannot be seen on a panoramic radiograph, a computer tomography (CT) scan should be taken to verify the location. The potential risks and complications of injury or damage to these vital structures should be included on the informed consent to avoid liability in cases of lawsuits.

Bartling et al. [24] observed 405 mandibular endosseous implants placed in 94 patients to determine the incidence of altered sensation using standard neurologic tests over a 6-month period. An incidence of $8.5 \%$ was found at the first postoperative appointment. 
Only 1 patient experienced complete anesthesia for 2 months. This was later resolved by 4 months.

\section{Cortical Plate Perforation}

The buccal cortical plate varies in thickness throughout the mouth and traumatic dental extractions can cause markedly thin plates or concavities, as well as overall ridge width deficiency [25].

\section{Sinus Membrane Complications}

In the maxillary posterior, the proximity of the sinuses 2627 can create a problem for dental implants if there is minimal residual crestal bone $(5 \mathrm{~mm})$ for stability. The maxillary sinus lift technique is an accepted procedure, demonstrated by Tatum, 28 to augment vertical height in the severely resorbed posterior maxilla area to facilitate proper implant placement. Sinus complications often occurred when the membrane is perforated at time of surgery.

\section{Peri-implantitis}

Biological failures include bacterial infections, microbial plaque buildup, progressive bone loss, and sensory disruptions [29, 31]. Biological complications are subcategorized into early biological failures and late implant failures, where the early failures are attributed to the failure of placing the surgical implant under proper aseptic measures $[31,34]$ and the late complications are typically peri - implantitis and infections bred by bacterial plaque $[35,36]$. The periimplant disease is also related to unequal occlusal load distribution, which may lead to loosening of the superstructure, infection of the surrounding area, eventually culminating into the inflammatory process [36]. Predisposing systemic conditions include uncontrolled diabetes mellitus, osteoporosis, smoking, long - standing treatment with steroids, uncontrolled periodontitis, radiation therapy, and chemotherapeutics $[37,38]$.

Clinical and radiographic symptoms of peri-implantitis [38]

- $\quad$ Probing depth $<6 \mathrm{~mm}$

- Bleeding on probing/suppuration

- Attachment loss/bone loss of $2.5 \mathrm{~mm}$

- Vertical destruction of crestal bone on radiographs

- Possible swelling and hyperplasia of the periimplant tissues

- Pain (unusual) if present, depicts acute infection

\section{Esthetic Complications}

Esthetic complications are common in implant therapy. These complications can include shade and contour issues and problems with recession, abutment margin placement, and implant positioning in the occlusogingival or mesiodistal dimensions [39].

\section{Conflicts of interest}

There are no conflicts of interest.

\section{CONCLUSION}

Despite the popularity of dental implants, the surgical placement of these implants is not a riskless procedure. Complications of dental implants are not obsolete and dental implant associated problems may not be apparent immediately. Proper training and planning are necessary in order to avoid complications. In the event that complications do arise, the surgeon should be equipped and knowledgeable to handle the emergency. To conclude, clinicians should develop new concepts in implant therapy considering all biologic and biomechanical factors, in conjunction with continuous training and improvement of their surgical skills to control and prevent implant complications. It is strongly recommended to avoid use of the many different implant systems without in-depth knowledge of the surgical and prosthetic armamentarium or thoughtful evaluation of each individual system.

\section{REFRENCES}

1. Douglass, C. W., Shih, A., \& Ostry, L. (2002). Will there be a need for complete dentures in the United States in 2020?.The Journal of prosthetic dentistry, 87(1), 5-8.

2. Murray, H., Locker, D., \& Kay, E. J. (1996). Patterns of and reasons for tooth extractions in general dental practice in Ontario, Canada. Community dentistry and oral epidemiology, 24(3), 196-200.

3. Reich, E., \& Hiller, K. A. (1993). Reasons for tooth extraction in the western states of Germany. Community dentistry and oral epidemiology, 21(6), 379-383.

4. Ong, G., Yeo, J. F., \& Bhole, S. (1996). A survey of reasons for extraction of permanent teeth in Singapore. Community dentistry and oral epidemiology, 24(2), 124-127.

5. Angelillo, I. F., Nobile, C. G., \& Pavia, M. (1996). Survey of reasons for extraction of permanent teeth in Italy. Community dentistry and oral epidemiology, 24(5), 336-340.

6. Balshi, T. J., Wolfinger, G. J., Stein, B. E., \& Balshi, S. F. (2015). A long-term retrospective analysis of survival rates of implants in the mandible. Int J Oral Maxillofac Implants, 30(6), 1348-1354.

7. Soto-Peñaloza, D., Zaragozí-Alonso, R., Peñarrocha-Diago, M., \& Peñarrocha-Diago, M. (2017). The all-on-four treatment concept: Systematic review. Journal of clinical and experimental dentistry, 9(3), e474.

8. De Angelis, F., Papi, P., Mencio, F., Rosella, D., Di Carlo, S., \& Pompa, G. (2017). Implant survival and success rates in patients with risk factors: results from a long-term retrospective study with a 10 to 18 years follow-up. Eur Rev Med Pharmacol Sci, 21(3), 433-437.

9. Thoma, D. S., Sailer, I., Ioannidis, A., Zwahlen, M., Makarov, N., \& Pjetursson, B. E. (2017). A systematic review of the survival and complication 
rates of resin-bonded fixed dental prostheses after a mean observation period of at least 5 years. Clinical oral implants research,28(11), 1421-1432.

10. Clark, D., \& Levin, L. (2016). Dental implant management and maintenance: How to improve long-term implant success. Quintessence Int, 47(5), 417-423.

11. Derks, J., Schaller, D., Håkansson, J., Wennström, J. L., Tomasi, C., \& Berglundh, T. (2016). Effectiveness of implant therapy analyzed in a Swedish population: prevalence of periimplantitis. Journal of dental research, 95(1), 4349.

12. Sennerby, L., \& Becker, W. (2000). Implant success versus survival.

13. Grisar, K., Sinha, D., Schoenaers, J., Dormaar, T., \& Politis, C. (2017). Retrospective Analysis of Dental Implants Placed Between 2012 and 2014: Indications, Risk Factors, and Early Survival. International Journal of Oral \& Maxillofacial Implants, 32(3).

14. Pjetursson, B. E., Thoma, D., Jung, R., Zwahlen, M., \& Zembic, A. (2012). A systematic review of the survival and complication rates of implantsupported fixed dental prostheses (FDP s) after a mean observation period of at least 5 years. Clinical oral implants research, 23, 22-38.

15. Goodacre, C. J., Bernal, G., Rungcharassaeng, K., \& Kan, J. Y. (2003). Clinical complications with implants and implant prostheses. The Journal of prosthetic dentistry, 90(2), 121-132.

16. Schwarz, M. S. (2000). Mechanical complications of dental implants. Clinical Oral Implants Research: Chapter 10, 11, 156-158.

17. Piattelli, A., Scarano, A., Piattelli, M., Vaia, E., \& Matarasso, S. (1998). Hollow implants retrieved for fracture: a light and scanning electron microscope analysis of 4 cases. Journal of periodontology, 69(2), 185-189.

18. Rangert, B., Krogh, P. H., Langer, B., \& Van Roekel, N. (1995). Bending overload and implant fracture: a retrospective clinical analysis. International journal of oral \& maxillofacial implants, 10(3).

19. CJ, G. (1999). Kan JY. Rungcharassaeng K. Clinical complications of osseointegrated implants. J Prosthet Dent, 81(5), 537-552.

20. Balshi, T. J. (1996). An analysis and management of fractured implants: a clinical report. International Journal of Oral and Maxillofacial Implants, 11(5), 660-666.

21. Eckert, S. E., Meraw, S. J., Cal, E., \& Ow, R. K. (2000). Analysis of incidence and associated factors with fractured implants: a retrospective study. International Journal of Oral \& Maxillofacial Implants, 15(5).

22. Sánchez-Pérez, A., Moya-Villaescusa, M. J., Jornet-García, A., \& Gomez, S. (2010). Etiology, risk factors and management of implant fractures. Med Oral Patol Oral Cir Bucal, 15(3), 504-508.

23. Liaw, K., Delfini, R. H., \& Abrahams, J. J. (2015, October). Dental implant complications. In Seminars in Ultrasound, CT and MRI (Vol. 36, No. 5, pp. 427-433). WB Saunders.

24. Bartling, R., Freeman, K., \& Kraut, R. A. (1999). The incidence of altered sensation of the mental nerve after mandibular implant placement. Journal of Oral and Maxillofacial Surgery, 57(12), 14081410.

25. Katranji, A., Misch, K., \& Wang, H. L. (2007). Cortical bone thickness in dentate and edentulous human cadavers. Journal of periodontology, 78(5), 874-878

26. Shin, H. I., \& Sohn, D. S. (2005). A method of sealing perforated sinus membrane and histologic finding of bone substitutes: a case report. Implant dentistry, 14(4), 328-335.

27. Kim, S. G., Mitsugi, M., \& Kim, B. O. (2005). Simultaneous sinus lifting and alveolar distraction of the atrophic maxillary alveolus for implant placement: A preliminary report. Implant dentistry, 14(4), 344-348.

28. Tatum, J. H. (1986). Maxillary and sinus implant reconstructions. Dental Clinics of North America, 30(2), 207-229.

29. Berglundh, T., Persson, L., \& Klinge, B. (2002). A systematic review of the incidence of biological and technical complications in implant dentistry reported in prospective longitudinal studies of at least 5 years. Journal of clinical periodontology, 29, 197-212.

30. Klinge, B., Hultin, M., \& Berglundh, T. (2005). Peri-implantitis. Dental Clinics, 49(3), 661-676.

31. Quirynen, M., De Soete, M., \& Van Steenberghe, D. (2002). Infectious risks for oral implants: a review of the literature. Clinical Oral Implants Research: Review article, 13(1), 1-19.

32. Snauwaert, K., Duyck, J., van Steenberghe, D., Quirynen, M., \& Naert, I. (2000). Time dependent failure rate and marginal bone loss of implant supported prostheses: a 15-year follow-up study. Clinical oral investigations, 4(1), 13-20.

33. Esposito, M., Hirsch, J. M., Lekholm, U., \& Thomsen, P. (1998). Biological factors contributing to failures of osseointegrated oral implants,(II). Etiopathogenesis. European journal of oral sciences, 106(3), 721-764.

34. Quirynen, M., \& Teughels, W. (2003). Microbiologically compromised patients and impact on oral implants. Periodontology 2000, 33(1), 119-28.

35. Tonetti, M. S. (1998). Risk factors for osseodisintegration. Periodontology 2000,17(1), 55-62.

36. Georgiev, O., \& Nogalchev, E. (2010). Local complications occurring during dental implantation. 
37. Prathapachandran, J., \& Suresh, N. (2012). Management of peri-implantitis. Dental research journal, 9(5), 516.

38. Albrektsson, T., \& Isidor, F. (1994). Consensus report: implant therapy. In Proceedings of the 1st European Workshop on Periodontology (pp. 365369). Berlin: Quintessence.
39. Wittneben, J. G., Buser, D., Salvi, G. E., Bürgin, W., Hicklin, S., \& Brägger, U. (2014). Complication and failure rates with implantsupported fixed dental prostheses and single crowns: A 10-year retrospective study. Clinical implant dentistry and related research, 16(3), 356364. 